\title{
Interlocking Nailing In Adult Femoral Shaft Fractures
}

\author{
${ }^{1}$ Dr M. Lakshmi Narayana,${ }^{2}$ Dr G. Veera Reddy, ${ }^{3}$ Dr N.Ravi Kiran, ${ }^{4}$ dr G. \\ Naresh. \\ ${ }^{I}$ Assistant Professor - Osmania Medical College -Hyderabad-Telangana \\ ${ }^{2}$ Assistant Professor - Osmania Medical College -Hyderabad-Telangana \\ ${ }^{3}$ Assistant Professor - Osmania Medical College - Hyderabad-Telangana \\ ${ }^{4}$ Resident-Osmania Medical College-Hyderabad-Telangana
}

\begin{abstract}
Fractures of femur in adult age groups above 18 years treatment mainly by internal fixation by inter locking nailing in present days . in the pas it is by cast, traction followed by casting, external fixation ,plating, enders nailing, intra medullary nailing ( $k$ nail )

But presently by more advanced interlocking nailing, by closed method, fracture hematoma and periosteum are not disturbed, with minimal incision for entry point of nail, nail and bone are locked by locking screws proximally and distally, so it gives rigid fixation and accurate anatomical alignment, that leads to early mobilization, early fracture healing, less complications and high patient satisfactory rate ${ }^{l}$.

This is prospective study of 28 patients with isolated femoral diaphyseal fractures in above 18 years age group with transverse short oblique and minimal comminuted fractures are treated . results are evaluated by radiological union, time of weight bearing and return to work, complication rate, patient satisfaction, and scoring by klemm`s criteria.
\end{abstract}

Keywords: inter locking nailing, Femoral shaft, adult age group.

\section{Introduction}

Femoral diaphyseal fractures in adult age groups (above 18 years) are 9.5 to 18.9 per one lakh population they are increasing because of urbanization ,increased road traffic accidents. These age groups having high displacing muscle forces , least remodeling capacity ,long union time, least tolarence, and high complication rate for prolonged immobilization physically and mentally, and also earning group for family causing more economic problem to family . so requiring good internal fixation implant and method for early mobilization with least complications.

In the past these age groups treated by plaster immobilization ,external fixator ,plating ,enders nailing and intramedullary nail $(\mathrm{k} \text { nail })^{3,4}$ these all having unacceptable results and high complication rates .but presently more advanced interlocking nails are used, they introduced by piriform fossa as entry with a small incision from tip of greater trochanter to proximally . and nail is locked proximally and distally with locking screws to bone, so that stability is maintained rotationally, trans axially, translationally ${ }^{1}$, this gives more rigid fixation . so that normal anatomical alignment of fracture is attained and maintained as this act as load sharing implant, Patient can be early mobilized . as this is performed in closed method not disturbing the fracture hematoma and periosteum, so that high union rates, least complications and high patient acceptability rate.

\section{Materials And Methods}

Patients of femoral diaphyseal fractures of above 18 years age group 28 in number are prospectively enrolled for study between November 2012 to april 2015 . in this study there were 20 males and 8 females, 15 are right sided and 13 are left sided, 16 are transverse and 12 are short oblique fractures, 6 are proximal ,15 are middle and 7 are lower part fractures ,20 are road traffic accidents , 8 are fall from a height and 20 are in 18 to 40 years age group, 8 are in 41 to 60 years age group.

\section{Inclusion criteria.}

a) above 18 years

b) transverse fractures

c) short oblique fractures

d) within 7 days old fractures

Exclusion criteria.

a) below 18 years

b) long spiral fractures

c) comminuted fractures 
d) associated injuries

e)end fractures

f)more than 7 days old

g) compound fractures.

\section{Operative Procedure}

After investigations and fitness taken patients were posted for surgery . under general or spinal anesthesia, supine position on fracture table or lateral position on plain table depending on patient obesity . patient on supine position traction is given the perineal post act as counter traction , foot is tied to foot plate , reduction is obtained and confirmed by c- arm for lateral position traction is applied for reduction after the guide wire enters the proximal fragment .

An incision of 6 to $8 \mathrm{~cm}$ is taken at tip of greater trochanter and extend proximally incision along the fascia of gluteus maximus taken and fibers are split piriform fossa identified, with awl entry is placed into femur at piriform fossa confirmed by c-arm and medullary canal opened guide wire is passed fracture alignment and rotation accurately maintained any rotation is corrected by comparing the proximal distal cortical thickening guide wire is passed till distal physeal scar, reamed with reamers till good resistance obtained, selecting the nail diameter $1 \mathrm{~mm}$ less than the last reamer ,length is measured preoperatively by from tip of trochanter to lateral joint line substracting 2 to 3 centimeters from it, or post operatively by substracting the out side guide wire length from total length or with length measuring guage . the proper nail selected is inserted on the guide wire . curvature of nail is anteriorly, handle is fixed which is on lateral side, this having two holes for proximal two screws which should be matched with the holes on nail ,now nail is inserted slowly with rotatory movements up to distal physeal scar and proximal end of nail at tip of trochanter . now nail position distally, proximally and fracture alignment confirmed. Distal two locking screws by free hand technique is applied confirmed by c-arm ap and laterally and also by guide wire inserting in the canal of interlocking nail getting the metallic sound and feel while hitting the screw, and also measuring from tip of the nail ,two proximal screws are applied with help of the jig, the most proximal screws is dynamic screw ,second one is static screw, dynamic screw only applied in transverse and short oblique fractures where stability of fracture reduction is good, stability is doubtful static lock also placed.

Postoperatively limb is elevated in the bed, after 48 hours pain is dicreased, patient sitting at the edge of bed knee flexion extension movements are started and slowly hip movements are started. encouraging the all movements of hip and knee . after 6 to 10 weeks partial weight bearing started, after 12 weeks full weight bearing started by examining callus formation and progression by Ap and lateral $\mathrm{x}$ - rays.

\section{Results}

All the 28 patients are available for evaluation ,they were followed for two years six months. Surgery time is one hour thirty minutes to two hours thirty minutes ,blood loss is $80-150 \mathrm{ml}$, hospital stay is 5-15 days ,partial weight bearing started 6-10 weeks and full weight bearing started after 12-20 weeks . radiological union by $12-24$ weeks, starting to go work by 16 weeks .

In this study there were two superficial infections which were healed, limb shortening below $1 \mathrm{~cm}$ in one patient three patient have below 5 degree angulation in distal fractures ,two below 5 degree internal rotation in proximal fractures ,all patients have near normal hip and knee movements, and normal muscle tone scoring by klemm `s ${ }^{2}$ scoring 22 are excellent, 5 are good one is fair no poor results are seen.

Proximal fractures the proximal fragment go into flexion external rotation, so placing entry into femur is difficult because of flexion and external rotation accurate reduction is difficult because of this requiring minimal incision for reduction, surgery time is more . so more complications in proximal fractures .

Middle fractures accurate reduction is easy so surgery time is less, all fractures in middle are healed well with least complications, distal fractures the distal fragment is wide, so nail will go to one side of the fragment causing more number of angulations so that requiring placing the nail in middle of the bone is important either by reduction or by putting polar screws.

\section{Discussion}

femoral fractures are more common in young age mainly by high velocity road traffic accident $\mathrm{s}$. this age group is mainly income source for the family. femur is the long, strong bone. It is mainly weight bearing bone in the body, surrounded by power full musculature which causes deforming forces on the fracture fragments, for early ambulation, less complications and nullifying these deforming muscle forces like trans axial, translation, rotatary forces and these age groups skeletal maturity completed so a good intra medullry implant is required. 
In the past femoral fractures are treated by plaster application, traction, external fixation, plating, ender $^{3,4}$ nailing, intra medullary nai (k-nail) ${ }^{5,6,7}$ having high complication rates . traction and plaster application, high malunion rates and high nonunion rates , prolonged hospitalization required.

External fixator is cumbersome pin tract infections, malunions ,non unions are high. prolonged immobilization required, more refractures. Enders rods also used in the past also having high complication rates.

Plating also used but it required long incision so fracture hematoma is lost and more periosteum stripping for plating required, leading to high infection rate, more refractures, required one more surgery for plate removal.

Intramedullary nailing ( $\mathrm{k}$ - nail) is another alternative, but rotatary stability is less so more complication rate and prolonged immobilization required .

Inter locking nailing is also intra medullary nail were nail is locked to bone with screws, so nullifying all deforming forces providing rigid fixation, early mobilization possible with least complications, operation can be done in minimal incision with closed method by not disturbing the fracture hematoma and periosteum $^{8,9,10,11}$.

In our study of 28 patients two superficial infections, one limb shortening of less than $1 \mathrm{~cm}$, three patients having angulation of less than 5 degrees two patients having internal rotation below 5 degrees, all fractures united.

In studies like kemp et $\mathrm{al}^{8}$, thoresens et $\mathrm{al}^{1}$, wiss et $\mathrm{al}^{9}$, bucholz et $\mathrm{al}^{6}$, brumback et $\mathrm{al}^{10}, \mathrm{klemm} \mathrm{etal}^{2}$ ,sojberg ${ }^{11}$ et al, get good results with interlocking nailing. Webb et $\mathrm{al}^{4}$, Johnson et $\mathrm{al}^{3}$, compared the traction , plaster, intra medullary nailing and inter locking nailing, they get good results in interlocking nailing. Winquist et $\mathrm{al}^{5}$, wolinsky ${ }^{12}$ et al, grosse $\mathrm{p}^{7}$ et al get poor results in intra medullry nailing

\section{V1. Conclusion}

Femoral shaft fractures above 18 years were skeletal maturity attained inter locking nailing is best treatment in view of of good clinical, radiological, cost effective results, high patient acceptance rates. The procedure being done by close method, minimal incision for entry of the nail, less blood loss, not interfering with fracture hematoma and periosteum with lest complications . strictly adhering to the principles and technique , makes this is the best treatment for femoral diaphyseal fractures in this age group.

\section{References}

[1]. Thoresen BO, Alho AN, Ekeland AR, Strømsøe K, Follerås G, Haukebø A. Interlocking intramedullary nailing in femoral shaft fractures. A report of forty-eight cases. JBJS Case Connector. 1985 Dec 1(9):1313-20.

[2]. Klemm KW, BÖRNER M. Interlocking nailing of complex fractures of the femur and tibia. Clinical orthopaedics and related research. 1986 Nov 1;212:89-100.

[3]. Johnson KD, Johnston DW, Parker BR. Comminuted femoral-shaft fractures: treatment by roller traction, cerclage wires and an intramedullary nail, or an interlocking intramedullary nail. J Bone Joint Surg Am. 1984 Oct 1;66(8):1222-35.

[4]. Webb LX, Gristina AG, Fowler HL. Unstable femoral shaft fractures: a comparison of interlocking nailing versus traction and casting methods. Journal of orthopaedic trauma. 1988 Jan 1;2(1):10-2

[5]. Winquist RA, Hansen ST, Clawson DK. Closed intramedullary nailing of femoral fractures. A report of five hundred and twenty cases. J Bone Joint Surg Am. 1984 Apr 1;66(4):529-39.

[6]. Bucholz RW, Jones A. Fractures of the shaft of the femur. J Bone Joint Surg Am. 1991 Dec 1;73(10):1561-6.

[7]. Grosse A, Christie J, Taglang G, McQueen M. Open adult femoral shaft fracture treated by early intramedullary nailing. Bone \& Joint Journal. 1993 Jul 1;75(4):562-5

[8]. Kempf I, Grosse A, Beck G. Closed locked intramedullary nailing. Its application to comminuted fractures of the femur. J Bone Joint Surg Am. 1985 Jun 1;67(5):709-20.

[9]. Wiss DA, Brien WW, Stetson WB. Interlocked nailing for treatment of segmental fractures of the femur. J Bone Joint Surg Am. 1990 Jun 1;72(5):724-8.

[10]. Brumback RJ, Ellison TS, Poka A, Bathon GH, Burgess AR. Intramedullary nailing of femoral shaft fractures. Part III: Long-term effects of static interlocking fixation. J Bone Joint Surg Am. 1992 Jan 1;74(1):106-12.

[11]. Sojbjerg JO, Eiskjaer S, Moller-Larsen F. Locked nailing of comminuted and unstable fractures of the femur. Bone \& Joint Journal. 1990 Jan 1;72(1):23-5

[12]. Wolinsky PR, McCarty E, Shyr Y, Johnson K. Reamed intramedullary nailing of the femur: 551 cases. Journal of Trauma and Acute Care Surgery. 1999 Mar 1;46(3):392-9. 